\title{
EKSPLORASI CERITA DAN VISUAL KARAKTER BERTEMAKAN ORANG TUA TUNGGAL UNTUK ANIMASI PENDEK
}

\author{
Claudia Sabrina $^{1)}$, Arik Kurnianto ${ }^{2)}$ \\ School of Design, Universitas Bina Nusantara \\ Jl. K. H. Syahdan No. 9, Kemanggisan, Palmerah, Jakarta 11480, Indonesia \\ ${ }^{1}$ Claudiasabrina.21196@gmail.com,2arikkurnia@binus.ac.id
}

\begin{abstract}
Abstrak
Keluarga merupakan tempat pertama untuk berinteraksi, belajar, dan mengungkapkan perasaan. Setiap anggota mempunyai peran mereka masing-masing dalam berkeluarga, tetapi perpisahaan dapat terjadi di antara mereka dalam hal apa pun, seperti perceraian atau meninggal. Sebagai pasangan pun tidak pernah membayangkan hal tersebut akan terjadi dalam hidupnya sehingga berdampak pada psikolog, seperti stress. Penggambaran terhadap situasi yang dialami oleh orang tua tunggal ini, penulis ingin membuat cerita dan karakter. Nantinya data yang sudah didapat akan digunakan sebagai hasil pendukung penulis dalam pembuatan workbook, laporan akhir, dan jurnal. Metode yang penulis lakukan untuk melakukan riset ini menggunakan teknik observasi dan wawancara. Atas dasar ini penulis ingin menghasilkan hasil eksplorasi karakter dan cerita dari penggambaran trauma dan stress yang dialami oleh orang tua tunggal dengan baik dan maksimal untuk pembuatan animasi pendek.
\end{abstract}

Kata Kunci: orang tua tunggal, ekplorasi, cerita, karakter

\begin{abstract}
The family is the first place to interact, learn, and express feelings. Each member has their own role in the family, but the separation can occur between them in any case, such as divorce or death. As a couple never imagined it would happen in his life so that it affects psychologists, such as stress. Depictions of the situation experienced by this single parent, the author want to make stories and characters. The data that has been obtained will be used as a result of author support in workbook creation, final report, and Journal. The method by which the author did to do this research uses observation techniques and interviews. On this basis, the author wants to produce the results of the exploration of characters and stories from the depiction of trauma and stress experienced by single parents well and maximally for the creation of short animations.
\end{abstract}

Keywords: single parents, exploration, story, characters

\section{PENDAHULUAN}

Dalam kehidupan berkeluarga tentu setiap anggotanya mempunyai peran masing-masing. Keluarga merupakan bagian penting dari kehidupan kita. Pengertian keluarga yang dikemukanan oleh Ki Hajar Dewantara (Ahmadi dan Uhbiyati, 2001) bahwa keluarga berasal dari kata sansekerta, yaitu kawula dan warga. Kawula yang mempunyai arti hamba dan warga artinya anggota. Di sini bisa diartikan bahwa setiap anggota dari kawula merasa sebagai satu kesatuan yang utuh dari dirinya dan juga bagian dari warga yang lainnya. Namun, bagaimana jika di antara suami atau istri dalam sebuah keluarga mengalami perpisahan dalam bentuk perceraian atau 
meninggal. Banyak orang tua yang mengalami hal tersebut dan salah satunya berdampak pada segi psikologinya dan juga anaknya. Ada juga korban yang diakibatkan oleh hal tersebut. Oleh sebab itu, penulis ingin mendalami untuk mengetahui hal ini.

Bercerita atau cerita merupakan komunikasi yang paling utama dan merupakan kultur manusia dalam bentuk verbal maupun berbentuk gambar. Hal ini dibuktikan dengan sudah dilakukan oleh manusia sejak 2500 tahun yang lalu dan bukti tersebut tergambar di gua Chauvet di Prancis Selatan. Menurut KBBI, cerita merupakan karangan yang menuturkan perbuatan, pengalaman, atau penderitaan orang; kejadian dan sebagainya (baik yang sungguh-sungguh terjadi maupun yang hanya rekaan belaka). Story atau cerita memiliki nilai positif dan mempunyai efek dibanyak bidang, salah satunya di dunia animasi. Cerita merupakan jiwa utama dalam sebuah film atau animasi, walaupun pergerakan animasi atau efek yang bagus dan visual atau design yang bagus tidak bisa membatu utuk menyelamatkan cerita yang buruk sehingga cerita merupakan hal paling penting dalam sebuah pembuatan animasi. Dengan memberikan struktur cerita yang baik akan membuat sebuah cerita menarik.

Dalam sebuah film, animasi ataupun komik pasti mempunyai pemain atau karakter yang akan memainkan perannya. Setiap karakter mempunyai ciri khas, terutama dari segi pakaian, bentuk tubuh, pose dan lainnya yang akan memberikan dampak bagi yang melihatnya. Menurut Kamus Besar Bahasa Indonesia (KBBI) online mennyebutkan bahwa karakter merupakan sifatsifat kejiwaan, akhlak atau budi pekerti yang membedakan seseorang dari yang lain; tabiat; watak. Tema mengenai orang tua tunggal ini jarang dijadikan sebagai animasi pendek dan hanya dijadikan sebagai animasi untuk edukasi. Dengan demikian, penulis ingin menyampaikan perasaan-perasaan yang dialami oleh seorang orang tua tunggal dengan menyampaikannya melalui penggambaran secara desain dan menarik. Selain aspek ini ternyata tema orang tua tunggal jarang diangkat ke depan publik secara umum dalam bentuk animasi pendek.

Penulis akan merancang animasi pendek bertemakan orang tua tunggal dengan mencari data lebih lanjut melalui medium kualitatif seperti wawancara dan observasi film. Maka dari itu penulis mengambil riset berupa eksplorasi cerita dan karakter sehingga penulis dapat menciptakan animasi pendek yang menarik dan dapat dinikmati oleh target penonton serta kalangan lainnya. Dengan pembuat riset pendek ini diharapkan dapat menambah pengetahuan kita tentang apa yang dirasakan oleh seorang orang tua tunggal.

\section{METODE PENELITIAN \\ Kajian Literatur \\ Teori Warna}

Warna merupakan suatu gejala yang terjadi ketika cahaya mengenani sebuah permukaan atau benda. Warna mempu memberikan keindahan, nilai estetika bahkan makna untuk memengaruhi pemikiran bagi orang yang melihatnya. Warna terdapat lingkaran warna yang akan memberikan harmoni warna. Terdapat 12 warna pokok yang terdiri dari warna primer, sekunder, dan tersier (Itten, 1970). Warna primer merupakan warna utama yang terdiri dari warna merah, kuning dan biru. Warna sekunder merupakan pencampuran antara 2 warna primer, seperti pencampuran warna kuning + merah menghasilkan warna oranye, kuning + biru menghasilkan warna hijau, dan merah + biru menghasilkan warna ungu. Dan warna tersier merupakan pencampuran antara warna primer dan sekunder seperti, pencampuran warna kuning+ oranye menghasilkan warna kuningoranye, kuning + hijau menghasilkan warna kuning-hijau, merah + oranye menghasilkan warna merah-oranye, merah + ungu menghasilkan warna merah-ungu, biru + ungu menghasilkan warna biru-ungu, biru+ hijau menghasilkan warna biru-hijau.

\section{Ekspresi Warna}

Warna juga dapat memengaruhi pemikiran bagi orang yang melihatnya sehingga warna merupakan salah satu alat untuk menyampaikan perasaan yang akan diberikan dalam sebuah animasi. Maka dari itu, semua warna mempunya arti tersendirinya. Dalam buku berjudul The Elements of Color (Itten, 1970) menjelaskan arti warna dan sebagai berikut: 


\section{Warna merah}

Mempunyai makna keberanian, kekuatan, kehangatan, energi, kegembiraan, maskulin, kehidupan, kehangatan, cinta, keinginan, gairah, darah, perang, agresif, amarah, tantangan, melawan, menuntut, pertarungan, brutal, kekerasan, bahaya.

\section{Warna biru}

Mempunyai makna stabil, kedalaman, kecerdasan, komunikasi, kepercayaan, efisiensi, ketenangan, loyalitas, logika, kesejukan, tenang, percaya diri, tulus, bersih, maskulin, lembut, dingin, acuh, murung, kaku.

\section{Warna kuning}

Mempunyai makna optimis, percaya diri, harga diri, kekuatan emosi, keramahan, kreatif, ceria, kebahagian, pengetahuan, kehormatan, kesetian, irasional, ketakutan, egoistik, depresi, cemburu, kecemasan, menghakimi, tidak sabar, warna yang menganggu penglihatan.

\section{Wara hijau}

Mempunyai makna harmoni, keseimbangan, kesegaran, alam, damai, kekayaan, pertumbuhan, aman, harapan, kurang berpengalaman, kelemasan, hambar, perselisihan, stagnasi (keadaan terhenti), materialistis, ambisi, keserakahan, cemburu, sakit, penakut.

\section{Warna ungu}

Mempunyai makna ketaatan, misteri, kemewahan, kualitas, kebenaran, sentimental, nostalgia, idealis, ambisi, mandiri, romantis, frustasi, penindasan, menghakimi, intoleransi, depresi, ketakutan, suram.

\section{Warna oranye}

Mempunyai makna kenyamanan fisik, sukacita, kehangatan, keamanan, gairah, kelimpahan, kesenangan, energi, antusiasme, saya tarik, bahagia, frustasi, ketidakdewasaan, perampasan, sembrono, sensualitas, dominasi, agresif, ketergantungan.

\section{Warna abu-abu}

Mempunyai makna netral, pengetahuan, kebijaksanaan, dewasa, kecerdasan, usia tua, kurang percaya diri, depresi, kurang energi, membosankan, melankolis, lifeless, dingin.

\section{Warna hitam}

Mempunyai makna kekuasaan, keanggunan, formalitas, kematian, kejahatan, kesedihan, misteri, penindasan, kedinginan, berat, ancaman, pesimis, kesedihan, takut, unknown, kematian, sering diasosiasikan negatif.

\section{Warna putih}

Mempunyai makna cahaya, kebaikan, kepolosan, kemurnian, keperawanan, bersih, kejelasan, kemurnian, kesederhanaan, efisien, aman, kedinginan, pembatas, kosong, terisolasi, membosankan, minimalis, sederhana, sering diasosiasikan positif.

\section{Color Wheel}

Color wheel atau roda warna merupakan salah satu alat untuk melihat keharmonisan suatu warna. Dalam color wheel terdapat beberapa nama untuk mencitrakan sebuah harmoni warna, yaitu monorcomatic, analogous, complementary, triad, split complementary, dan tetrad. Monokromatik merupakan harmoni warna yang tercipta dari warna yang sama dari warna paling terang ke gelap. Analogus merupakan harmoni warna yang tercipta dari 3 warna yang bersebelahan seperti contohnya merah, merah-oranye, dan oranye. Complementary merupakan harmoni warna yang tercipta dari 2 warna yang berseberangan, seperti kuning dan ungu. Triad merupakan harmoni warna yang tercipta dari 3 warna yang membentuk segitiga sama sisi. Split 
complementary merupaka harmoni warna yang tercipta dari 3 warna, hampir menyerupai triad, tetapi tercipta segitiga sama kaki. Tetrad merupakan harmoni warna yang tercipta dari 4 warna yang membentuk kotak atau persegipanjang.
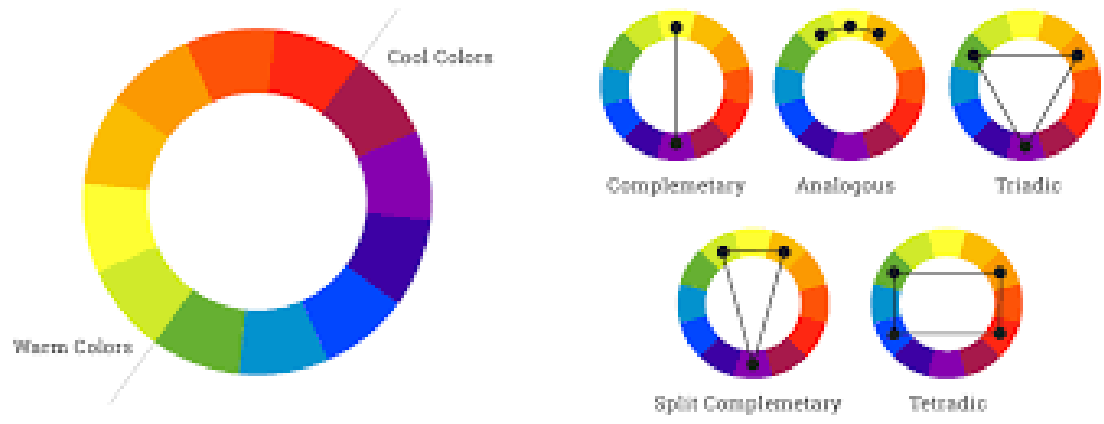

Gambar 1 Color Wheel dan Skema warna

\section{Character Design}

Dalam sebuah film, animasi ataupun komik pasti mempunyai pemain atau karakter yang akan memainkan perannya. Setiap karakter mempunyai ciri khas terutama dari segi pakaian, bentuk tubuh, pose dan lainnya yang akan memberikan dampak yang melihatnya. Dalam pembuatan karakter animasi terdapat bentuk dasar yang mempunyai makna tersendiri. Menurut Nieminen, M (2017) dalam tesisnya dengan judul Psycology In Character Design Creation of a Character Design Tool, mengatakan bahwa bentuk dasar mengkontribusi sangat besar dalam pembuatan karakter desain. Bentuk dasar di antaranya adalah kotak, segitiga, dan bulat. Ketiga bentuk ini memberikan makna yang berbeda, seperti kotak mempunyai makna stabil dan solit. Selain itu, kotak mempunyai sisi yang lebar sehingga memberikan kesan simetris dan susah untuk digerakan. Penggunaan bentuk kotak biasanya lebih untuk pembuatan karakter Super Hero, polisi atau karakter yang memliki sifat yang kuat. Segitiga mempunyai makna tajam, aktif dan diasosiasikan sebagai suatu yang tidak setabil. Pada bentuk segitiga, sering digunakan untuk membuat karakter protagonis karena bentuk tajamnya yang membuat penonton tidak nyaman untuk melihatya. Lingkaran mempunyai makna bersahabat karena di dalam lingkaran tidak mempunyai ujung yang tajam. Selain itu, juga melambangkan kesatuan dan kesempurnaan. Karakter yang menggunakan bentuk lingkaran biasanya menjadi karakter yang bersahabat dan lucu.
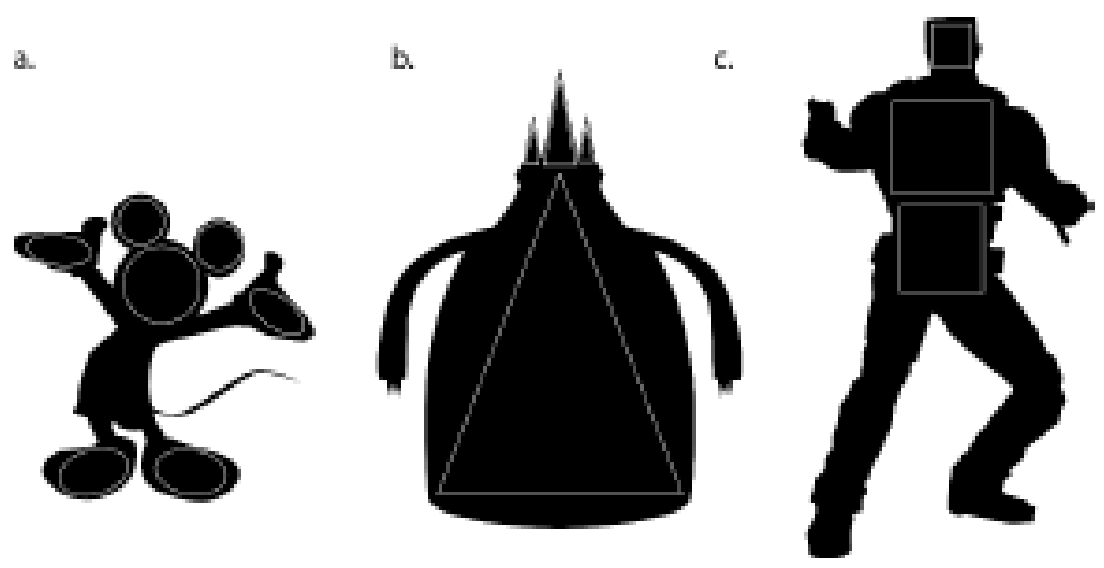

Gambar 2 Perbedaan bentuk dasar

Menurut Tillman (2011) dalam bukunya yang berjudul Creative Character Design "The first pieces in good character design are these core principles, known as archetypes. Archetypes represent the personality and character traits that we as humans identify with. There are many different archetypes, ....." maka sebelum pembuatan sebuah karakter desain membuat cerita 
dibalik karakter lebih mudah dikenali dan hal ini juga memudahkan untuk pembuatan dan mengembangkan sebuah cerita karena si karakter mempunyai tujuannya dan latar belakang.

\section{Teori Cerita}

Banyak hal yang dapat memengaruhi dalam pembuatan cerita, seperti yang dikatakan oleh White, T (2009) dalam buku How to Make Animated Film megatakan bahwa pembuatan cerita bisa berasal dari berbagai macam ide, dengan menulis konsep, dan mengekplorasi segala aspek yang mendukung cerita.

Dalam pembuatan cerita yang menarik, sebuah cerita harus mempunyai struktur yang akan membuat cerita tersebut menjadi menarik. Aristoteles mengatakan "A plot must have, a beginning, a middle, and an end, and the events of the plot must causally relate to one another as being either necessary or probable." (Arlond dan Eddy, 2007). Jadi, dalam cerita terdapat permulaan tengah atau terjadinya sebuah konflik dan ending yang bisa berupa resolusi. Terdapat piramit pembuatan sebuah cerita yang diciptakan oleh Gustav Freytag (1816-1895) merupakan penulis novel dan screenwriting dari German.

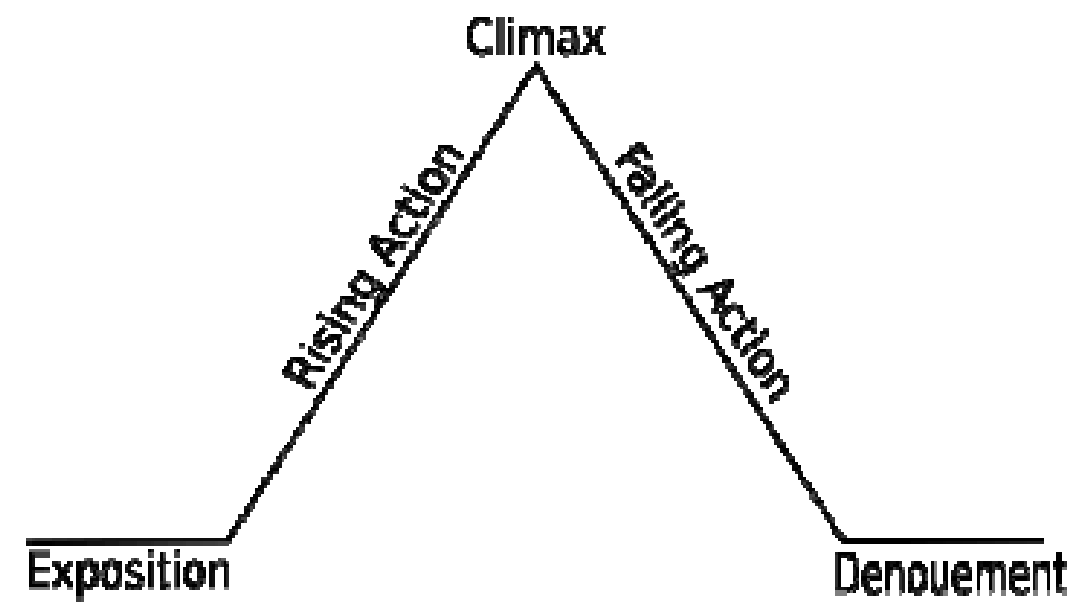

Gambar 3 Piramit Freytag

Dalam piramit ini, terdapat 5 bagian penting dalam pembuatan cerita, seperti Exposition, Riding Action, Climax, Falling Action, dan Denoument. Selain piramit Freytag terdapat konsep pembuata cerita yang lebih sederhana dibandingkan dengan piramit Freytag, yaitu "Three Act Structure" (Arnold and Eddy, 2007). Terbagi menjadi 3 bagian, yaitu Act 1, Act 2, dan Act 3. Act 1 merupakan permulaan dari sebuah cerita. Dalam bagian ini pembuatan cerita memperkenalkan karakter, tempat, dan konflik yang sedang dialami. Act2 merupakan bagian tengah dari sebuah cerita. Di sini konflik sudah memmuncak dan si karakter sudah mencari solusi dari masalah tersebut. Dan Act 3 merupakan bagian akhir cerita yang berisi tentang resolusi dan jalan keluar dari masalah tersebut. 


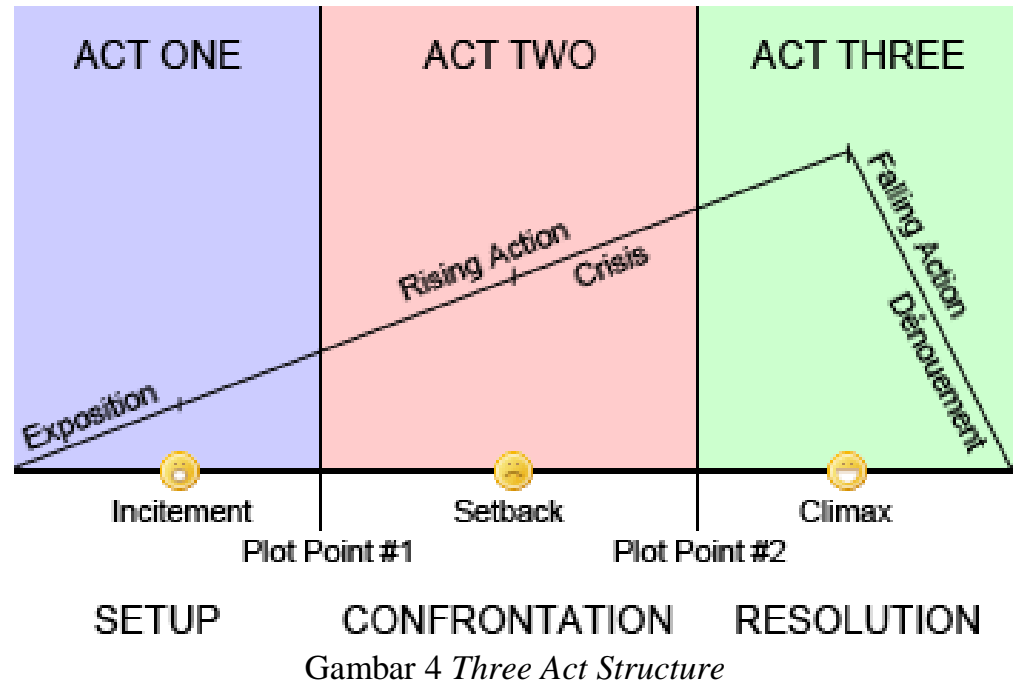

Dalam pembuatan cerita yang baik terdapat beberapa elemen yang dapat memdukung dalam pembuatan sebuah cerita yang baik. Menurut Philips dan Huntley (2001) di dalam buku Dramatica a New Theory of Story, karakter merupakan salah satu elemen penting dalam sebuah cerita. Dalam karekter terdapat pembagiannya, yaitu Prontagonis, Antagonis, Impact Character dan Reason and Meaning Character. Protagonis meupakan karakter yang menjadi pemeran utama dalam sebuah cerita dan karakter yang mencoba serta menyelesaikan sebuah masalah untuk mencapai tujuan dalam sebuah cerita. Penggunaan karakter protagonis biasa dijadikan sebagai karakter utama dalam pembuatan cerita. Antagonis merupakan karakter yang mempunyai tujuan yang bertolak belakang dengan karakter protagonis dalam menyelesaikan masalah atau tujuannya. Impact Character mempunyai tujuan yang sedikit berbeda dengan karakter Antagonis. Impact Character mempunyai tujuan yang lebih menggangu atau menghalangi karakter utama dalam menyampai tujuannya. Fungsi pengguaan Impact Character digunakan agar karakter utama tidak menggunakan jalan yang mudah untuk mencapai atau menyelesaikan masalahnya. Reason and Meaning Character merupakan 2 karakter yang berbeda dan bertolak belakang. Reason character merupakan tipe karakter yang lebih terorganisir dan logis menggunakan daya pikirnya untuk menyelesaikan sebuah masalah dan untuk menyampai tujuannya. Emotional character merupakan karakter yang tidak terorganisir dan didorong oleh perasaan untuk menyelesaikan masalah atau mencapai tujuannya.

\section{Metode Perancangan Cerita}

Metode perancangan cerita akan penulis buat dengan menggunakan data-data dari hasil wawancara narasumber dan observasi dari film yang mempunyai tema menyerupai.

\section{Metode Penelitian \\ Kualitatif}

Metode penelitian Kualitatif merupakan penelitian yang bersifat deskriptif atau berdasarkan analisis sebuah data. Menurut Kamus Besar Bahasa Indonesia (KBBI) kualitatif merupakan sesuatu yang berdasarkan mutu. Jadi, kualitatif tidak bisa dihitung melainkan dirasakan oleh peneliti tersebut.

Tujuan penulis menggunakan metode kualitaif ini karena akan memecahkan permasalah dengan cara mengkajinya. Selain itu, penulis juga akan mengumpulkan data berdasarkan hasil wawancara tema dengan narasumber, professional, dan juga mengobservasi film yang mempunyai tema menyerupai, dan studi kepustakaan, agar penulis dapat mengerti lebih dalam apa yang dialami oleh orang tua tunggal dan juga mengetahui siapa saja yang menjadi korban dalam hal ini. 


\section{Teknik Pengumpulan Data Observasi}

Penulis akan melakukan pengumpulan data dengan menggunakan teknik observasi dari beberapa film dan animasi pendek dari segi karakter (personalty), cerita, desain karakter dan warna mood. Penulis juga akan mengobservasi referensi karakter dan desain. Hal ini dilakukan agar penulis mendapatkan inspirasi dalam membuat animasi pendek.

\section{Wawancara}

Dalam riset yang penulis lakukan, penulis akan mewawancarai dosen psikologi, narasumber yang mengalami untuk mendapatkan data mengenai gejala, korban, perasaan yang dialami dan pengobatannya. Dosen Psikologi yang penulis wawancara adalah Antonia Pantja Juni Wulandari, S.Sos., M.Si. yang merupakan Dosen Psikologi dari Universitas Bina Nusantara. Beliau merupakan Deputy Head of Psicology dari Universitas Bina Nusantara. Dan Noni sebagai narasumber yang menjadi orang tua tunggal sebagai data pendukung dalam research ini. Hasil dari wawancara dengan narasumber dan Dosen Psikologi akan penulis gunakan untuk mendukung dari segi ekplorasi cerita dan karakter. Untuk visual 2D penulis mewawancarai senior dari Universitas Bina Nusantara mengenai, cara dan proses pembuatan animasi 2D, kekurangan dan kelebihan dari animasi 2D, tips and trick dari pembuatan animasi 2D, yaitu Fieranny Halita. Beliau membuat karya animasi yang berjudul wewe dan masuk ke dalam film festival. Data ini membantu penulis untuk menciptakan animasi 2D dengan cara-cara yang sudah diberikan.

\section{Studi Kepustakaan}

Studi kepustakaan akan dilakukan penulis dengan meneliti tentang pembuatan cerita yang baik dan menarik, dengan didasari oleh teori cerita dan teori lainnya yang saling berkaitan. Selain perancangan cerita, penulis juga meneliti desain karakter dan warna dengan mengumpulkan teori yang bersangkutan. Pengumpulan teori yang penulis lakukan diambil dari buku-buku, website, jurnal, dan laporan yang bersangkutan.

\section{HASIL DAN PEMBAHASAN \\ Hasil Data Wawancara}

Dalam kegiatan wawancara ini, penulis mendapatkan data dan informasi mengenai perasaan orang tua tunggal dari ahlinya, seorang ahli psikologi yang bernama Antonia Pantja Juni Wulandari, S.Sos., M.Si. Beliau merupakan dosen dan Deputy Head of Psikolog di Universitas Bina Nusantara, yang berlokasi di Kampus Kijang, Jakarta. Berdasarkan hasil wawancara dengan beliau, penulis mendapatkan beberapa kesimpulan:

1. Orang tua tunggal merupakan orang tua yang harus melakukan 2 peran sekaligus dalam kehidupannya untuk membesarkan anaknya.

2. Penyembuhan (Healing) pada orang tua tunggal tidak bisa disamakan dengan orang tua tunggal yang lainnya sehingga penyembuhan bisa beda-beda tergantung penyebabnya karena setiap yang mengalaminya mempunyai pengobatan yang personal.

3. Dari hasil tindakan ini salah satu yang menjadi korban hal ini adalah anak

4. Anak adalah salah satu yang menjadi alasan orang tua tunggal untuk berjuang menjalani hidup karena anak merupakan tanggung jawab orang tua tunggal

5. Pilihan yang dipilih oleh orang tua tunggal merupakan merupakan keputusan mereka sendiri karena orang tua tunggal sudah mengetahui konsekuensi yang dialami oleh dirinya.

Selain melakukan wawancara dengan Antonia Pantja Juni Wulandari, S.Sos., M.Si. penulis juga melakukan wawancara dengan narasumber yang bernama Noni. Beliau menjadi orang tua tunggal dikarenakan berpisah dengan pasangannya. Berdasarkan hasil wawancara dengan beliau, penulis dapatkan kesimpulan:

1. Orang tua tunggal khususnya dari segi ibu mereka sangat memperhatikan banyak hal, seperti ekonomi, peran ganda, membesarkan, dan memberikan kasih sayang kepada anaknya 
2. Karena tidak ada pendamping atau partner dalam hidupnya, orang tua tunggal yang tidak berkerja akan bingung dengan perekonomian

3. Orang tua tunggal akan melakukan apa saja demi bisa membesarkan anaknya dengan segala cara.

4. Orang tua tunggal juga merasakan rasa takut jika anaknya mengalami hal seperti bully-an dari sisi eksternal

5. Orang tua tunggal mengalami trauma dan stres karena pilihan yang ambil dapat memengaruhi kehidupan mereka.

\section{Hasil Data Observasi}

Dalam kegiatan ini, penulis melakukan observasi film yang mempunyai tema serupa, yaitu film "The Florida Project" garapan Sean Baker pada tahun 2017 dan "3 Billboards Outside Ebbing Missouri" film garapan Martin McDonagh pada tahun 2017. Dalam film "The Florida Project", penulis dapat menyimpulkan:

1. Hayle selalu menutupi segala sesuatu kepada anaknya dalam hal apa pun

2. Hayle melakukan segala cara agar bisa membiayai kehidupan anaknya supaya tetap merasa senang dengan memberikan material

3. Hayle melakukan segala sesuatu dengan cara apa pun agar anaknya tetap bahagia

4. Diumurnya yang masih muda, si Mooneee tidak mempunyai panutan untuk dirinya sendiri. Maka dari itu, Hayle merupakan contoh dan panutan hidup bagi dirinya

Dan dalam film “3 Billboards Outside Ebbing Missouri” penulis mendapatkan kesimpulan seperti berikut:

1. Mildred rela melakukan apa pun terhadap kematian anaknya agar kasus tersebut mendapatkan kejelasan dan keadilan

2. Walaupun tindakan Mildred banyak menerima tentangan terutama dari keluarganya sendiri, dia tetap melakukannya demi keadilan

3. Mildred tidak bisa menjelaskan alasan kenapa si anak tidak bisa melakukan hal apa yang Angela mau

\section{a. Hasil Visual}

Dari hasil wawancara dan observasi, penulis mendapatkan data dan menganalisis serta menyimpulkan hasilnya sehingga penulis bisa merancang visual dari tema, seperti berikut:

\section{Penulisan Judul}

Dari hasil observasi, judul film animasi yang penulis tetapkan sebagai referensi menggunakan font "Potato and Peas"dan "Pensil Grid". Hal ini penulis pilih karena font memberikan kesan hangat dan friendly pada tulisan "MOM" dan goretan yang tidak beraturan pada "STER" memberikan kesan yang tidak nyaman dan mengganggu.

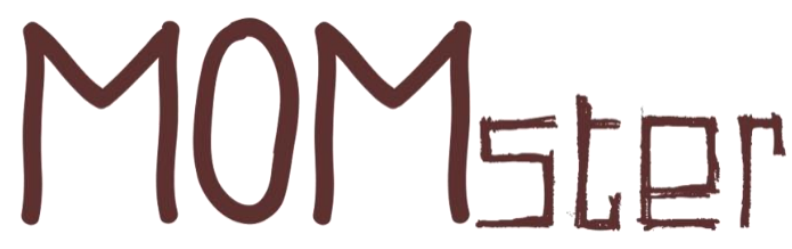

Gambar 5 Typerface Judul

\section{Perancangan Karakter}

Anita

Tokoh utama dalam cerita animasi pendek ini merupakan Anita yang merupakan seorang ibu tunggal dan membesarkan anak perempuannya yang bernama Mentari. Nama Anita diambil karena nama tersebut mempunai arti kuat karena karakter Anita akan melewati masa yang 
sulit dan harus menyembunyikan rasa trauma dan stres yang dialami olehnya yang disebabkan oleh perpisahan. Anita mempunyai sifat yang hangat dan penyayang terhadap anaknya, walaupun dirinya lama-lama akan termakan oleh rasa trauma dan stres tersebut. Karakter Anita penulis desain agar terihat seperti orang tua dengan memberikan rambut yang beruban dan memberikan sedikit kerutan di bagian mulut. Gaya rambut Anita yang dikuncir tidak kencang lebih memberikan kesan keibuan.

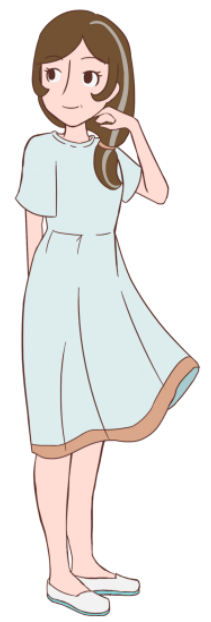

Gambar 6 Karakter Anita

\section{Mentari}

Tokoh utama kedua dalam cerita animasi pendek ini merupakan Mentari, anak dari Anita. Mentari merupakan anak berumur 6 tahun yang mempunyai karakter periang, innocent dan suka bereksplorasi. Mentari mempunyai rambut kuncir dua yang memberikan kesan anak yang innocent dan periang. Warna yang dipilih juga merupakan warna yang terang seperti kuning karena memberikan kesan periang dan cerah. Nama Mentari mempunyai arti matahari karena matahari memberikan kesan yang ceria dan membawa keceriaan.

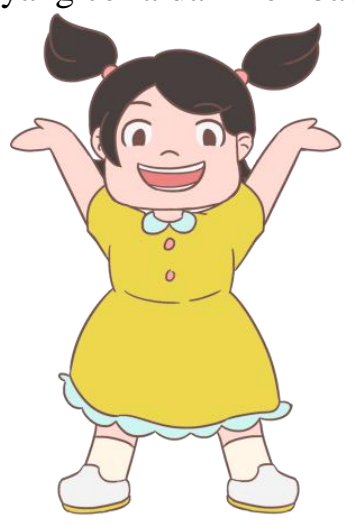

Gambar 7 Karakter Mentari

\section{Arong}

Tokoh antagonis dalam animasi pendek ini merupakan Arong. Karakter Arong ini merupakan penggambaran dari rasa stres dan trauma yang dirasakan oleh Anita. Desain Arong mempunyai karakter misterius dengan menggunakan warna hitam dan merah memberikan kesan berbahaya. 


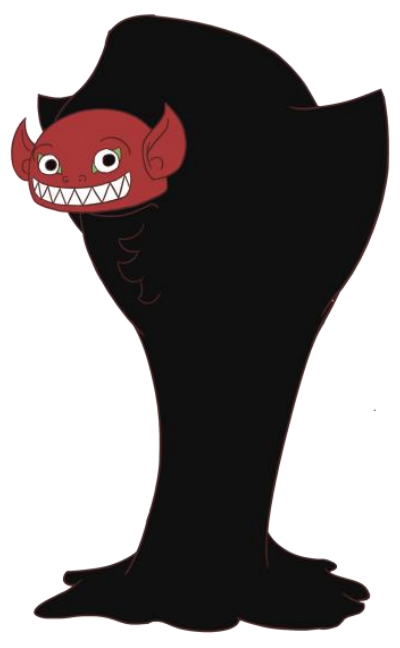

Gambar 8 Karakter Arong

\section{SIMPULAN}

Penelitian yang dilakukan untuk mendapatkan jawaban-jawaban dari pertanyaan dan masalah yang dicari, yaitu mengetahui apa yang dirasakan oleh orang tua tunggal ketika berpisah oleh pasangannya serta dirancang menjadi sebuah cerita dan karakter. Hal tersebut penulis cari dengan menggumpulkan data wawancara mengenai orang tua tunggal dan observasi film yang mempunyai tema sejenis, berikut merupakan kesimpulan,

1. Dari hasil tindakan ini salah satu yang menjadi korban hal ini adalah anak

2. Anak adalah salah satu yang menjadi alasan orang tua tunggal untuk berjuang menjalani hidup karena anak merupakan tanggung jawab orang tua tunggal

3. Orang tua tunggal akan melakukan apa saja agar bisa membesarkan anaknya dan membuat mereka bahagia

4. Orang tua tunggal tidak mau memperlihatkan kesedihannya di depan anaknya karena takut membuat mereka khawatir.

5. Penyembuhan (Healing) orang tua tunggal dibeda-bedakan bergantung penyebabnya karena setiap yang mengalaminya mempunyai pengobatan yang personal

Berdasarkan data-data yang dikumpulkan, maka penulis dapat membentuk cerita yang berdasarkan tema dan tercipta karakter Mentari, Anita, dan Arong. Karakter Anita berdasarkan sifat penyayang dan rela melakukan semuanya. Karakter Arong yang merupakan gambaran rasa stres yang akan menyakiti Mentari dan menjadikannya korban.

Animasi merupakan medium komunikasi penulis untuk menyampaikan informasi secara visual dan juga sebagai sarana hiburan bukan hanya untuk anak-anak atau remaja juga melainkan untuk kalangan umur lainnya. Dengan ini penulis ingin menyampaikan pesan yang mendalam tentang orang tua tunggal.

\section{DAFTAR PUSTAKA}

Ahmadi, A. H., \& Uhbiyati, N. (2001). Ilmu pendidikan. Jakarta: Rineka Cipta.

Arnold B, \& Eddy, B. (2007). Exploring visual storytelling. New York: Thomson Delmar Learning.

Itten, J. (1970). The element of color. Ravensburg: Van Nostrnnd Rotnhold Company.

Kamus Besar Bahasa Indonesia [Online]. Diakses dari https://kbbi.kemdikbud.go.id/entri/ karakter 
McDonagh, M. (Directed). (2017). Three billboards outside ebbing missouri. [Video]. United Kingdom: Fox Searchlight Pictures, Film4 Productions, Blueprint Pictures, Cutting Edge Group.

Nieminen, M. (2017). Psychology in character design: Creation of a Character Design Tool. (Tesis). Bachelor of Culture and Arts, South-Eastern Finland University of Applied Sciences.

Philips, M. A., \& Huntley, C. (2001). Dramatica a new theory of story. Burbank California: Screenplay Systems Incorporated.

Baker, S., Bergoch, C., Chinoy, K., Duncan, A., Saks, A., Silvestri, F., \& Tsou, S-C. (Producer). (2017). The florida project. [Video]. Amerika Serikat: Cre Film.

Tillman, B. (2011). Creative character design. United Kingdom: Focal Press.

White, T. (2009). How to make animated films. Burlington: Focal Press. 